\title{
PLANKTON: A New Theory of Organization for the 21st Century
}

\author{
Dr. Javier Simonovich \\ The Max Stern Yezreel Valley College, Israel \\ Dr. Moshe Sharabi \\ The Max Stern Yezreel Valley College, Israel \\ Dr. Ofer Arian \\ The Max Stern Yezreel Valley College, Israel
}

\begin{abstract}
Theories of the organization were extensively researched during the $20^{\text {th }}$ century and are still important at $21^{\text {st }}$ century. We explain the behavior of organizations and then propose an innovative and creative perspective through the pronunciation of PLANKTON organization theory, which responds to the new needs and developments of organizations human services in the technological and global world in which we live. The organizational PLANKTON theory is a theoretical perspective that has been developed by the authors during the last fifteen years as a result of an intensive advisory work to human service organizations and College teaching at the Human Services, Sociology and Political Science departments in Israel. PLANKTON theory of organization proposes eight theoretical concepts through which the understanding of the theory is possible. The eight concepts are planning, learning, achievable, norms, knowledge, technology, opportunity and natural.
\end{abstract}

Keywords: organization theories; innovation; administration; planning, organization management

\section{INTRODUCTION}

Organizational theories have been extensively researched and developed during the twentieth century and continue to be of great importance in the twenty-first century, explaining organizations' behaviors in the face of the challenges of the technological boom.

This paper will present a historical overview of the main theoretical currents of the organization and then propose an innovative and creative perspective through the pronunciation of PLANKTON Organization theory, which responds to the new needs and developments of human services organizations in the technological and global world in which we live.

The PLANKTON Organizational theory is a theoretical perspective that has been developed during the last fifteen years as a result of an intense work of advising to human service organizations, and extensive of university teaching experience in the f Human Services, Sociology and Political Science departments at the Yezreel Valley College (YVC) in Israel.

\section{ORGANIZATIONAL THEORIES IN THE TWENTIETH CENTURY}

Organizational theories developed during the twentieth century parallel to the processes of technological, social, political and ideological development that occurred after the Industrial Revolution of the nineteenth century. The different theories presented by different researchers 
of the organization were based on the particular area of work in which they grew up and acquired their professional perspective and their philosophy of life.

In order to understand in an orderly, systematic and concise manner the most important organizational theories, their particular contribution and their influence over time, the theories will be presented through an organizational taxonomy (See organization chart No.1). This taxonomy is based on theoretical and conceptual Weiner, (1990) ${ }^{1}$ contributions who makes an extensive review of the different theories including classic and emerging theories.

The first organizational theories at the beginning of twentieth century are called classic theories. From them arise the emerging theories that are based and derived from the classical ones.

20th Century Organizational Theories

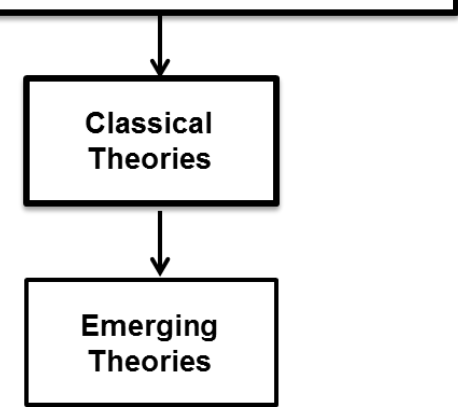

\section{Organizational Chart No.1: Organizational Theories of the 20th Century ${ }^{2}$}

The classic organizational theories are those that arose in the early twentieth century. From the mid-twentieth century, emerging organizational theories $t$ combine different aspects of classical theories. They delve into their special focus and some particular aspects of the theories according to the technological advances and ideological changes that took place after the Second World War. To be able to understand the taxonomy of the organization's theories, the classical theories are divided into two sub-groups: a) Traditional Organizational Theories; And b) Traditional Systemic Theories (See organization chart No. 2).

\section{Traditional Organizational Theories}

Traditional Organizational Theories comprise four different theoretical perspectives:

1) Bureaucratic; 2) Scientific Management; 3) Administrative Management; 4) Human Relations.

On the other hand, traditional systemic organizational theories also include four additional theoretical perspectives:

1) General System;2) Structural Functionalism;3) Organizational psychology; And 4) Sociotechnical Systems.

\footnotetext{
1Myron E. Weiner, Professor Emeritus of the School of Social Work, Institute of Public Services and the Master's Program in Public Relations from the University of Connecticut, USA. Author of several books and articles on the use of technology in public administration and non-profit. As a member of the Weiner Associates LLC, Prof. Weiner provided administrative and organizational consulting to national and international governmental and non-profit.

${ }^{2}$ Adaptation of the authors of the theories presented by Weiner, 1990.
} 
The German sociologist Max Weber (1945), who first analyzed the bureaucratic model of the organization, described the basic qualities of organizations: division of labor, vertical and constant hierarchy, definition of norms and regulations, and formal exchange channels of information.

The perspective of scientific management was studied cautiously in the United States by the engineer Frederick Winslow Taylor and published in 1911 (Taylor, 1945).Taylor proposes the maximization of the profits by means of a meticulous study of quantification and calculation of all the conducts necessary to be able to realize a task. His basic perspective is that human beings are motivated almost exclusively by economic remuneration.

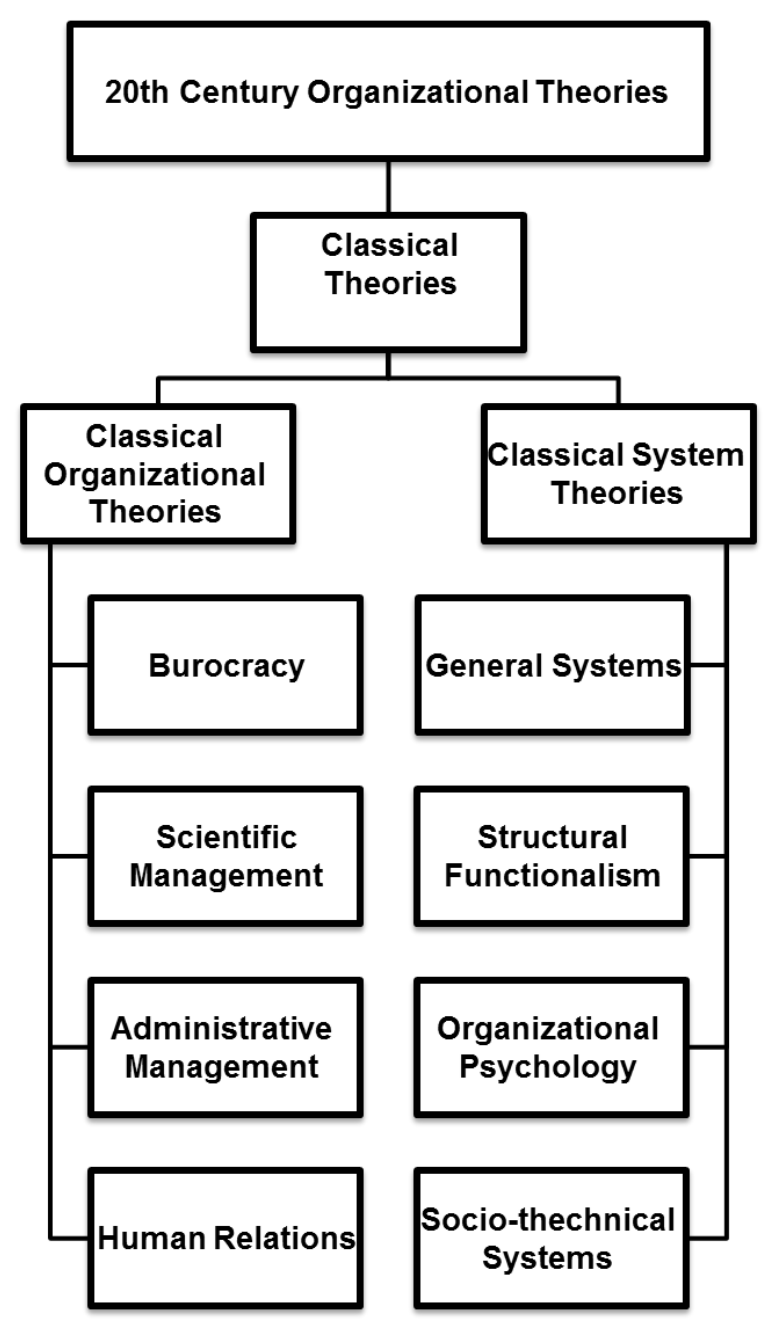

\section{Organizational Chart No.2: Traditional Systemic and Organizational Classical Theories ${ }^{3}$}

Unlike the two previous theories, whose pillars were Taylor and Weber, several researchers contributed to the theory of the administrative management in Europe and in the United States. Some of the most outstanding were Luther Gulieck (the father of the American administration) and Lyndall Urwick (respected theorist of the organization in Great

${ }^{3}$ Adaptation of the authors of the theories presented by Weiner, 1990. 
Britain). According to the perspectives of both authors, the administrative management tries to answer the question what is the work of the executive leadership in the organization. The answer is presented with the acronym POSDECORB that its letters mean: Planning, Organizing, Staff training, Directing, Coordinating, and Reporting. These actions engaged by the organization leaders shows their responsibility and commitment to the better functioning and budget of the organization (Gulick \& Urwick, 1937).

Human relations theory is the fourth classical organizational theory, considered more as a social movement based on the humanistic perspective. This perspective profoundly influenced human organizations and societies taking into account the fulfilment of personal and social needs of the individuals who activate in these organizations. For the first time in the history of organizations, the human relations theory centered on the informal aspects of human relations and investigated this as an important component in achieving the requested performance of the work teams. One of the most outstanding forerunners of human relations in organizations was the social worker and theoretician of the philosophy of administration, Mary Parker Follet (1924), who can be considered the progenitor of the administration of human services in the United States And in the world.

\section{Classical System Organizational Theories}

Silverman, (1971), classified classical System Organizational Theories (CST) (See organization chart No. 2). It is important to clarify that the division between classical organizational theories and classical system theories is artificial since both sets try to understand and analyze the way in which human beings interrelate in groups and organizations in the social environment. The division is then practical and pedagogical in order to be able to understand the differences and emphasis of each theory. CST theories take from biology the concept of a system composed of different identifiable and interacting organs that adapt themselves to the surrounding environment in order to survive and act in it. The main point of analysis will be the whole as a system or the perspective of the system in its functional way and not centered on its parts separately.

The General Systemic Theory (GST) developed by the biologist Ludwig von Bertalanffy, (1968) during the 50 s of the twentieth century, is an attempt to synthesize organizational evolution into a conceptual theory that contributes to understanding human systems. The GST helps us to explain the different organizational processes through the interrelation and interdependence of the different organization components.

At the same time as GST, influenced organizational social thinking, Structural Functionalism (SF) provided another interesting perspective of organizational theories. While the theory views society and organizations as a system, the focus is on how organizations and institutions survive despite permanent changes in the natural and social environment. Talcott Parsons (1949), one of the most prominent SF theorists, proposed a paradigm that included the concepts of adaptation, goal reaching, integration and latency (AGIL). According to the Parsons paradigm, a social system acts as a network of interrelated subsystems that work together to provide the needs of each subsystem.

In the mid-twentieth century, a new school of systemic organizational theories called organizational psychology (OP) arose following the rise of different psychological trends. In their theoretical basis, the theories sought new techniques that improve the internal dynamics of the organization, promote group acceptance and collaboration, and improve work through participation in decision-making. Among the most prominent representatives is Abraham 
Maslow (1954) who described the hierarchy of human needs. The physiological needs, the need for personal security, the need for belonging and social status, and finally the need for self-realization. The theory raises the existence of basic conflicts between the needs of the organization and the individual needs of its workers. These conflicts, unlike previous theories that proposed the adaptation of the individual to the situation, approach and solve the conflict modifying the organizational structure to suit the person's needs. Therefore, the optimal organization situation is when it provides the objectives and the personal and organizational needs through organizational participation.

The sociotechnical systemic theories (STS) added three dimensions to the understanding of human needs in the organizations. 1) Different organizational environments and frameworks determine human behavior. 2) There is no one single form of organization appropriate for all situations.3) Organizational formal structures and informal social relationships within and outside the organization are crucial for the proper functioning of the organization. These dimensions of the sociotechnical perspective are emphasize in the interrelation between technology, environment, feelings of the members of the organization and the organizational structure. During the 1950s Joan Woodward (1958) proposed that organizational structures and processes depend largely on the available technology and on the organization's own environment. He concluded that organizations are open systems that react dynamically to the different environmental demands of technological change.

\section{Emerging Organizational Theory}

Based on the rich contributions of the different classical theories, from the middle of the twentieth century until its end we can identified the Emerging Organizational Theories (EOT). The theories are presented under three main currents of thought (See Diagram No. 3) ${ }^{4}$ :

- Behavioral sciences;

- Management sciences;

- Contingent or situational theories.

${ }^{4}$ Adaptation of the authors of the theories presented by Weiner, 1990 


\section{Classical Theories}

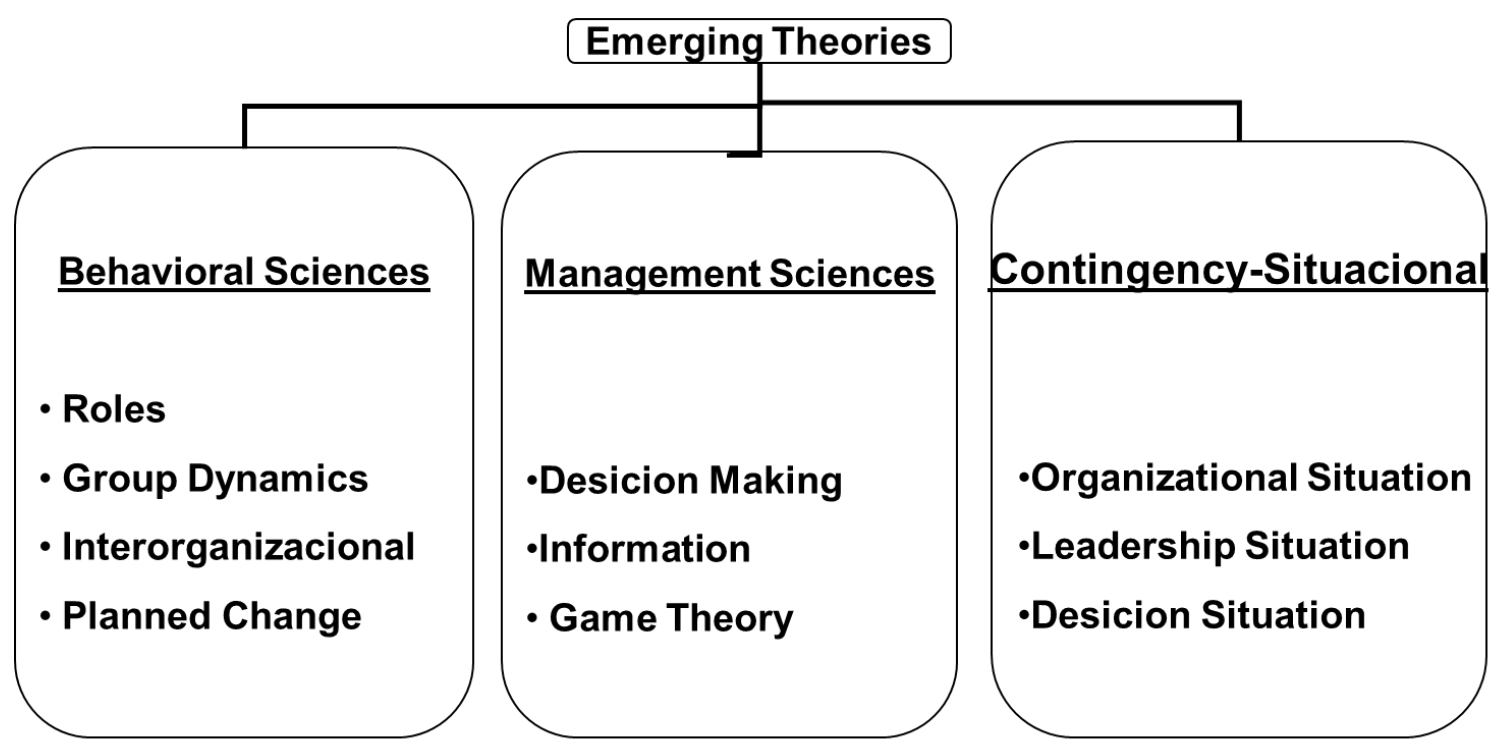

Organizational Chart No. 3: Emerging Organizational Theories

These theories encompass and deepen different theoretical and practical aspects of classical theories, adding and accentuating along the last twentieth century years, new elements and innovative scientific perspectives.

Emerging theories from behavioral science focus on four aspects:

1) Human roles

2) Group dynamics

3) Interorganizational relations

4) Planned and constant change

Human Role theory holds that each person performs a large number of roles during his life, sometimes at the same time or different roles according to the different stages along the life cycle. Therefore, role theory is the meeting point between psychology and sociology where the individual psyche and social demands interrelate. Each person fulfills a series of roles according to their location and socio-economic status. These roles determine the person's behavior in the different organizations and social situations in which he participates (Merton, 1968). The study of individual roles cannot be separated from the study of group dynamics. Humans interact in small groups that comprise a distinctive dynamic. Kurt Lewin (1948), considered the father of group dynamics, introduced the perspective and technique of group dynamics analysis in every organization under the motto "there is nothing more practical than a good theory."

Mutual interdependence is one of the characteristics of modern man's life in the complex societies in which we live. In turn, organizational interdependence has developed where organizations are much less autonomous and interdependent. The Interorganizational 
relations theory (IRT) is characteristic of post-industrial societies where there is a service economy, highly professional and pluralistic. Thompson \& McEwen (1958) identified four types of processes that govern Interorganizational relationships: inter-organizational competition, negotiation, co-optation, and coalition building.

If continuous change is the only constant in the Universe it will be the same in the societies and organizations in which we live.In 1961 the book Planning for Change (Bennis, at. All) presented two trends of intellectual thinking. On one side, that of the organizational psychologists interested in managing the processes of change and the conflicts in the organizations, and on the other side urban planners dedicated to planning and delineating the organizational parameters and tasks of the future. Therefore, planned change theory (PCT) sees planning as an integral part of the social process. This process must be rational to be able to draw a clear policy, based on the constant changes of the organizational structures, and finally, evaluable and quantifiable.

The emerging theories of management sciences are very broad and diffuse. However, we classify them according to their professional area of origin and main interest. The theory of decision-making bases its perspective on concepts, proposals and techniques that see the organization as a decision managerial entity. Simon (1960) divides decisions into two types: programmed and routine decisions; and unexpected and intuitive decisions. The manager of the organization should focus his decision tasks based on his own professional knowledge and information. This is achieved, using computers and application of cybernetic theory in a highly scientific and measurable perspective.

Game theory, part of the premise that relationships between organizations are like games of strategy. The applications range from competitive games and wars to economic or social games. Participants are "actors" responsible for maximizing their profits. John von Neumann and Oskar Morgenstern (1944) published for the first time the theory in a comprehensive form. Since then until today, it has become a basic theory in the understanding organizations and interrelationships in a global world.

The contingent-situational emergent theory holds that every day and in a casual way, the organization faces different situations that must be solved. The organizational situations creates a delicate and interrelated design of technical and social aspects within the organization adapted to the needs required by each situation. The organizational leadership situations forces each manager in the organization to adapt his leadership style to the specific requirements of the situation created, to those he must lead (including each of his subordinates). Leadership is a dynamic process that is constantly changing (Hersey \& Blanchard, 1977). The decision-making situations at different levels of organizational management require an active participation in the decision making by the work team.

We have presented here an extensive description of the main theories of the organization developed during the twentieth century. These theories function as basic theoretical infrastructure and framework for the new theoretical proposals of the XXI Century. Therefore, in the following section we will present the proposed PLANKTON theory of organization.

\section{PLANKTON - THEORY OF THE ORGANIZATION}

It is clear that the theories developed during the twentieth century are not mutually exclusive but complementary one to the other. Each theory contributed some aspects that were of greater consideration to the place and time in which this theory emerged, or by the researcher 
or organizational scientist who applied it. It is so that the organization theory here proposed called PLANKTON lies on more than one hundred years of theoretical and practical research of the organizations done by all those precursors that studied organizations befor us.

Plankton in nature is the basic unit of the food chain in the whole world. If Plankton were to disappear by some natural catastrophe or by a hecatomb created by human civilization, almost all forms of life existing and known today would quickly disappear from the face of the earth. That is why plankton is the basis of the ecological chain of marine and terrestrial life. Plankton is a general name given to microscopic organisms that float drift according to the sea currents in the different oceans. The plankton is composed mainly of algae that obtain their energy by means of photosynthesis, and by protozoans that feed on particles and the algae itself. This is why Plankton is generally divided into phytoplankton (organisms that take its energy from the sun) and zooplankton (organisms that take their energy from other organisms).

A person without scientific knowledge and without high fidelity instruments and technology can hardly visualize the plankton. Due to its microscopic size, it is impossible to see the units that form it at a glance without the use of a microscope. In addition, it is equally impossible to understand the magnitude and influence of plankton on life on Earth, without taking a perspective of thousands of miles above the sea, preferably with airplanes or satellites that circumambulate planet Earth from the stratosphere.Curiously, the largest living creature today is the blue whale which measures between 24 and 27 meters and weighs between 100 and 120 tons, is fed almost exclusively by plankton (krill, zooplankton and phytoplankton). All living forms on the planet relate to the food chain based on plankton. Therefore, plankton is the basic form of life in the world, as we know it today.

PLANKTON's theory of organization takes the initials of the word PLANKTON as a basic acronym. In this way, each letter generates a professional concept applied in the understanding of human service organizations today. The word plankton, metaphorically speaking explains the basic, elementary and necessary components in a modern organization by applying the plankton qualities above described.

Just as plankton is the basis of life, every organization must be able to define its own plankton, or basic and minimal unit of life that allows organizational performance, without which the organization would perish. Each organization must be able to understand the dynamic behavior created by internal organizational activity and its influence on the interorganizational environment. Identifying that minimum and basic component is not an easy task. It requires a wide range of theoretical knowledge of the organizations and a deep analysis of the specific organization to which we refer. This process parallels the scientific contemplation of plankton through the microscope (analysis and description of organizational unit) and perspective observation from the atmosphere (analysis and description of general organizational dynamics).

To be able to approach the theory of PLANKTON organization it is necessary to write the acronym PLANKTON in such a way that each letter relates itself with the initial of the theoretical concept to which it refers (see Table No.1 below). Next to each concept, there is a short explanation. 


\begin{tabular}{|l|l|l|}
\hline & Concept & \multicolumn{1}{c|}{ Explanation } \\
\hline$\underline{\mathbf{P}}$ & Planning & Planning a project, to make a plan \\
\hline$\underline{\mathbf{L}}$ & Learning & Learning possibilities, knowledge, science, wisdom \\
\hline$\underline{\mathbf{A}}$ & Achievable & Feasible, executable, can be achieved \\
\hline$\underline{\mathbf{N}}$ & Norms & Standards, model rule, typical shaping unit \\
\hline$\underline{\mathbf{K}}$ & Knowledge & Knowledge availability, skills, tools, expertise \\
\hline$\underline{\mathbf{T}}$ & Technology & Available state of the arts technology \\
\hline$\underline{\mathbf{O}}$ & Opportunity & Opportunity, timely, convenient \\
\hline$\underline{\mathbf{N}}$ & Natural & Natural, simple, genuine, spontaneous \\
\hline & & \\
\hline
\end{tabular}

Table No.1: Acronym Plankton and its concepts (Adaptation of the authors)

The use of the acronym PLANKTON to name the organization theory suggests that the "Planning gives the Tone" (plan-k-tone). Meaning that a correctly traced plan generates the tone, sound or result of the organization purpose and its correct performance. A PLANKTON organization is then one that in all its aspects identifies itself with the components of each of the acronym concepts. Such organization can describe the implementation of these concepts from its minimum indispensable expression at the workers personal level, to its maximum manifestation and influence in the inter-organizational environment. We will expand and explain below the PLANKTON concepts.

\section{Planning}

Planning in a human services organization is the basic tool that defines the course and the way to carry out the task of the organization. The area of project planning is a highly professional one, to such an extent that there are specialists in planning and managing projects. That is why those who are responsible for running the organization must have substantial knowledge and experience in project planning.

The planning pyramid (See Figure No.1) helps us to understand the organizational process that begins in planning, materializes in the accomplishment of the work to do and culminates with an evaluation of what has been accomplished as planned. At the end of this cycle, a new planning process begins, based on the achieved goals and the evaluation that provides the needed feedback to the organization to continue the growth process of the organization life cycle.

The first task in an existing organization or in front of a new project, the process of creative thinking within the organization should be encouraged (see figure 1). This process takes relatively less time than all other stages but is of fundamental importance. The graphical representation of the pyramid cusp infers that having the smallest surface takes less time than the other stages of the general process. On the other hand, unlike the three-dimensional construction of a real pyramid, this organizational process begins hanging the creative thinking process in the air, where imagination and dreaming are the best support for an original and innovative beginning. 


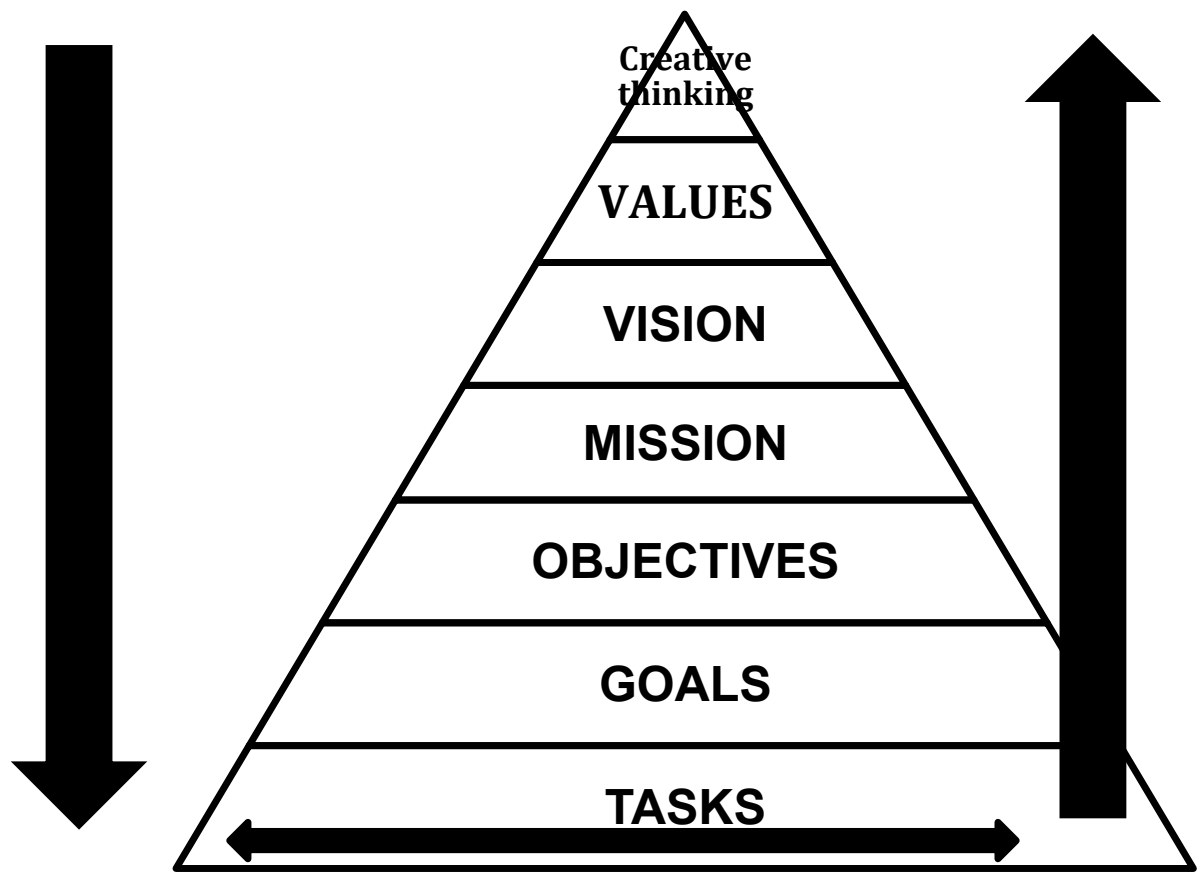

Graph no.1: Planning pyramid (Adaptation of the author)

This planning process will decrease its altitude and increase its surface until reaching the base of the pyramid where the real and concrete actions take place through the organization's staff. That is, the abstract tasks take less time, and most time will be used in the realization and concretization of the organizational activity or project.

After the creative thinking process, and many times simultaneously, the organization must define, the values shared by the members of the organization and expected behaviors that correspond to and emanate from these values. Values are generally the ideological framework on which the organization's activity lies. Among the most common values we can mention justice, truth, security, transparency, service, punctuality and professionalism. After designating the common values of the organization, they use them to write the vision and mission of the organization. In a university or college organization, for example, the values will be education, knowledge and equality as a frame for the educational contents implemented as vision and mission of such institution.

The vision of the organization is a phrase that includes each of the values and abstractly denotes a narrative of the point of maximum success that the organization tends to achieve. Each organization must understand the essence of its own vision and mission. For example, the vision of a university could be, "The University tends to achieve the best education possible by providing the widest knowledge to its students, as the best way to promote equality of opportunities among the citizens." Therefore, the mission of the university will be to train teachers and students, providing them with the necessary infrastructures for scientific research in order to get closer every day to the aspirated and desired vision.

Once the vision and the mission are set, the desired objectives derived from them. The definition of organizational objectives is a task that includes theoretical and practical resources. Objectives definition use abstract concepts that are not quantifiable. The objective must create a desired causality and behavioral change, passing from one situation to another determining the course of action but not the measurable goal. The objective of the university 
will be "To train young students in academic, professional and technological areas that open for them a satisfactory career and rewarding job in the labor market". This definition is clear but at the same time abstract and does not include quantifiable parameters.

To achieve operational goals the organization should draw them from the different objectives. The basic difference between objective and goal is that goals must be measurable and hence their operability. If a goal cannot be measured, it is not a goal, and it has no sense of being. The units of measurement can be time, weight, length, height, level of knowledge, score on a test, quantification of behaviors etc. It is imperative that for each objective there is at least one goal. An objectivel without a goal has no sense of being. Returning to the university example, students at the university can define their goal "To reach a university degree in three years with an average score above 85 points". Another goal would be "90\% of the students who begin their studies at the university will be able to finish them and receive their degree within four years.

Each of the goals will be transform in specific actions or behaviors that the management, administrative staff, clients and suppliers of the organization will perform to meet the goals set. The university's day-to-day actions include college classes, research, marketing and advertising, daily maintenance and cleaning. All these actions are necessary for the fulfillment of the goals of the university. Returning to the graphic illustration of the planning pyramid, then we can infer that the wider portion and largest area of the pyramid is the action stage or recurrent behavior. These behaviors should be evaluated by measuring tolls applied sporadically and at the end of each preset period of activity.

Summarizing the process, we can see the planning cycle starting in the creative thinking stage at the top of the pyramid. After that, descending through the various stages (vision, mission, objectives, goals) to concrete action to again retake all stages Ascending to a redefinition of the process ( see the arrows on the No.1 chart). If the actions were successful we reached the goals. If the goals were achieved it means that we meet the objectives. If the fulfilled the objectives, we probably carried out our organizational mission and we are approaching the desired institution vision, based on the clear organizational values. Then we can restart a new planning process through a new creative thinking process.

\section{Learning}

The learning process is a continuous shaped staircase-ascending spiral shaped. Since the first performance of newborn baby until the complicated tasks performed by adults in their daily lives, everything is learning. An organization that has no ability to learn and to teach its members may not prolong its life. Each manager, officer, coordinator or operator in an organization should know that his professional training is constant and unending. At the same time, the organization itself has to have training programs and career planning courses for its members.

Human capital in today's organizations is of paramount importance since most of the knowledge and skills are in the heads of the members of the organization and not necessarily on computers and machinery. Wisdom and study the organization provides its members are an endless motivational source. In the example of the university, the learning process is incessant and it depends on the survival of the organization as such. 


\section{Achievable}

Every organization in the fast-paced world and dynamic where we live in the XXI century has to increase the feasibility of its goals. Managers in the twentieth century were content to maintain the status quo, or generating moderate gains. Today the rapid pace of change, forces the new managers to implement and achieve organizational objectives in a much faster path. The only constant in the universe is change, proclaims the theory of planned change. Therefore, to achieve the goals set by the organization is not the only task, but to achieve a goal or objective should immediately make the manager to reconsider a change of perspective that leads to new objectives and goals. Has perhaps the university, as it exists today, the maximum feasibility to subsist and survive during the entire twenty-first century? What structural changes should carry out the college to achieve optimal performance and reach its newly objectives and goals? These are questions to formulate to any $21^{\text {st }}$ Century organization.

\section{Norms}

Norms, standards or patterns of behavior of organizations are created to achieve the best possible organizational objectives, taking into account the influence of the norms on staff organization and vice versa. The norms are not established unilaterally, but through democratic dialogue within the organization taking into account the interests of all its stakeholders. This way the organization creates unique and specially adapted models not only to the organization, but also to each situation and even to each employee. These norms are transformed into basic and typical shaping units of the organizational plankton. While the units are difficult to identify at first glance, they influence the success of the organization on the long run and in large scale. Norms as well as plankton, can be identified by looking at the units of conduct of the employees in their daily work, or they can be identified at large taking the proper perspective away from organizational units to a comprehensively observation of the organization behavior at the inter-organizational environment.

Organizational norms are compiled into instruction manuals and codes of behavior. These norms are explicit or formal rules, which indicate the expected performance of the organization. However, there are other rules that are not explicit, declared or written in clear compendia. These norms are informal and determine the organizational culture of the institution. Informal norms are woven through time and passed from generation to generation of workers. They manifest in the daily behavior of workers, are crucial, difficult to change, and based primarily on personal example of management ranks. The success or failure of an organization can be greatly due to the postulates by formal norms and the definition of the particular style of informal norms that exist in the organization.

\section{Knowledge}

Knowledge is power. In the technological society in which we live having knowledge and expertise in any subject, is an indisputable advantage in the race to success and objectives achievement. Organizations must have at least two broad and deep areas of knowledge. The first area is the market or technological theme in which the organization acts. The second area is the art of directing and business management. The organizational knowledge, codified in manuals and computerized in data banks of "Cloud Technology". But organizational wisdom mainly lead managers and employees of the organization in their heads. That's why human capital must be carefully promoted and secured by the organization. Each of the members of the organization work like a puzzle piece, where each tab has its colors, its design and qualities that contribute to the organizational task ut is worthless alone. Combined harmoniously each part of the puzzle, create the whole picture as a gestalt. This allows optimum use of knowledge 
and facilitates to reach the desired goal. The parts of the puzzle create the whole picture (a gestalt), allowing the best utilization of knowledge in general and to reach the desired goals.

\section{Technology}

Technological know-how of the organization is the practical basis of plankton organization. The secret of survival of every living organism is adapting to internal and external changes. Proposed by the theories of the twentieth century, still happens in every organization that functions as a living organism. Changes in the XXI century are becoming faster and more frequent to such an extent that human nature is difficult to adapt to such changes and organizations behave as such. Rapid progress has left behind economic empires based on outdated technologies and has promoted a new economy and technological companies that were created on new technological standards in a relatively short time. We see technological advances in all areas. In the field of science and medicine, precision instruments and the incessant use of information technologies to improve living standards. Technological dependence leads organizations to survive in the environment only if they constantly update their information technology and teams on an inter-organizational level. This same dependency can succumb entire organizations in natural disasters or mega terrorist attacks as happened in the Twin Towers terrorist attack in New York in September 11, 2001. So the race behind the technology is mandatory for every organization and determining its own survival. The human factor and technology policy applied by the managers is paramount. Consequently, a university that does not renew its technological resources will no longer be attractive to new students and disappear quickly.

\section{Opportunities}

Every organization must march forward. Failure to do so will most likely make it stay in the same place or go backwards. Thus, the growth and development of the organization are almost constant and binding. Organizations and their members are in a continuous search for opportunities. As the plankton that seems to travel to drift where ocean currents transport it, but in fact, the plankton seeks directions where it can be most useful to its member units as a whole. In this way fulfills its function in the best way possible to serve its members and the general environment. Organizations also seek opportunities that arise in their path to fulfill its role towards its members within the inter-organizational environment in which exists. Opportunities are those events that usually allow in a planned way, and sometimes in a spontaneous and surprising way, to take advantage of organizational resources and stakeholders, which when combined, catapult the organization to previously unexpected directions.

Opportunities should be identified, cataloged and utilized at the right moment for the benefit of the organization and its vision. The organization should create awareness on each of its members for the expected opportunity that will come at any time. Otherwise, the opportunity could be lost and probably another organization will be able to capitalize it.

\section{Natural}

Mother Nature is wise and powerful. The proper use of natural resources and moderate exploitation are the best lesson that an organization can learn. Plankton is interminable by satellite from space. The main beneficiaries of their abundant presence appear to be only the huge blue whales that eat tons of plankton per day. However, the plankton never ends thanks to an almost perfect ecological balancing in the use of natural resources. Every organization should plan balanced exploitation of natural resources (materials, land, water, air, minerals, animal hunting, fishing etc.) in a context of organizational ecology. That is, the ability to 
integrate itself in the ecological chain trying to create continuity and avoiding own extinction and surroundings. The natural task of the organization begins with the internal management of existing resources, recycling and re-using disposable materials and obsolete machinery. Planning to reduce waste generation allows the perpetuity of the life of the organization and its products generated by its member units. The trend toward natural perspective in the PLANKTON organization can generate a tendency to organizational survival and continuity desired for many years to come.

\section{CONCLUSIONS}

The PLANKTON organization theory presented in this paper, proposed in an innovative way a different perspective of the theoretical frameworks known and developed during the twentieth century. There is no doubt that classical theories and emerging theories are the indisputable basis of the knowledge required for effective administration in the organizations created in the last century. Nevertheless, the great and accelerated changes perceived from the beginning of the XXI century demand us new proposals that try to frame the new organizational challenges that we face.

We can make conclusions in the following points:

1. There is nowadays the need for wide and multidisciplinary knowledge of those professionals who pretend to understand the organizational behavior in the Interorganizational framework of the XXI century for a better representation of them. Information is the capital they count on and the possibility of manipulating such information is the challenge faced by the managers of human service organizations. The theoretical baggage of the twentieth century, composed of classical and emerging theories, is the basis of the proposal, which combined with the insights of the new plankton theory presented here, can provide an innovative and practical organizational perspective.

2. The acronym plankton as the leading title of the proposed theory responds to the growing need to enunciate concepts that are sufficiently dynamic and creative as well as current and attractive. In today's human society, the changes happen at an extremely rapid pace and sometimes almost unattainable. The endless human creativity helps us not only to propose as a solution the adaptation to the changes but also contributes to follow the discovery of new technologies and new trends. The marketing of goods and services depends on the quality offered as well as the way in which are presented. That is why PLANKTON's theory of organization raises an innovative proposal using a concept according to the guidelines currently required and established in 21st century society.

3. PLANKTON's theory of organization uses eight concepts defined as basic to be able to approach the theory: planning, learning, achievable, norms, knowledge, technology, opportunities and natural. Plankton as the basic unit of life on Earth is a metaphoric basic unit of the life of the organization. Without being able to identify and promote the organizational plankton, the whole organization is in danger. Serious and professional approaches to each of the concepts is essential for the survival of the organization. The paper presented concrete examples addressing how to apply the eight basic concepts.

4. The research of organizations in the 21st century and the development of new theoretical concepts based on such research has to continue on a balanced combined academic work in universities and substantial field practice. The PLANKTON theory of organization forged for years through this double experience carried out by the authors. The practice of organizational consulting in private and public non-profit institutions provided the necessary field experience. The academic work of research, teaching and 
learning in universities provided the theoretical framework. This combination is suggested as a requirement for future developments of new theories of the organization. PLANKTON's theory of organization tried humbly to present an alternative conceptual framework, which can help us in the incessant task of bridging the professional gap to adapt to the world today.

\section{BIBLIOGRAPHY}

WG Bennis, Benne KD, Chin R., \& Corey KE, eds. (1961). The Planning of Change New York: Holt, Rinehart \& Winston.

Follet MP (1924) Creative Experience. New York: Longmans, Green.

L. \& L. Gulick Urwick (1937) Papers on the Science of Administration . New York: Institute of Public Administration.

P. Hersey \& Blanchard KH (1977) Management off Organizational Behavior: Utilizing Human

Resources . Englewood Cliffs, NJ: Prentice Hall.

K. Lewin (1948) Resolving Social Conflicts: Selected Papers on Group Dynamics . New York: Harper \& Row.

Maslow A. (1954) Motivation and Personality . New York: Harper \& Row.

RK Merton (1968) Social Theory and Social Structure . Ney York: Free Press.

Parson T. (1949) The Structure of Social Action . Glencoe Ill.:Free Press.

Silverman D. (1971) The Theory of Organizations: A Sociological Framework . New York: Basic Books.

Simon H. (1960) The New Science of Management Decisions. New York: Harper \& Row.

FW Taylor (1945) Scientific Management. New York: Harper \& Row.

JD W. Thomson \& McEwen (1958) Organizational Goals and Environment: Goal Setting as an Interaction Process. American Sociological Review , Feb. 1958, 23, No. 1, pp. 23-31

Von Bertalanffy L. (1968) General System Theory: Foundations, Development, Applications . New York: Braziller.

Von Neumann \& Morgenstern J. O. (1944) Theory of Game \& Economic Behavior . Princeton, NJ: Princeton University Press.

Weber M. (1945) The Theory of Social and Economic Organizations . Glencoe, Ill. Free Press.

Weiner ME (1990) Human Services Management: Analysis and Applications. The Dorsey Press, Homewood, Illinois.

Woodward J. (1958) Management and Technology . London, HSMO 